\title{
Anticipated Pain Before and During Orthodontic Treatment
}

\begin{abstract}
Sabitha.I
Summary: The aim of this study was to compare the anticipated pain before and during orthodontic treatment. 23 adolescent patients were selected and a counselling was given about the pain to the patients who are going for an orthodontic treatment. The level of anticipation of pain before initiation of orthodontic treatment were measured by Visual Analogue Scale . After the initiation of treatment patient is recalled after one week ,and the level of experienced pain is measured and compared.

Introduction:

The international association for the study of pain has defined it as an unpleasant sensory and emotional experience associated with actual or potential experience associated with actual or potential tissue damage. Orthodontic treatment is always taken as a painful procedure by patients even before the start of the treatment. However the intensity of pain differs from patient to patient, it depends upon age ,sex ,race,emotional state and cultural background. Periodontal pain was caused by a process of pressure,ischaemia,inflammation and oedema .Orthodontic treatment exerts pressure on teeth due to which prostaglandins are released which are the mediators of inflammatory process and hence pain. The purpose of the study is to compare the anticipated pain before starting orthodontic treatment to the intensity of pain experienced following orthodontic treatment which is measured by VAS scale.Visual Analogue Scale is a straight horizontal line of fixed length usually $10 \mathrm{~cm}$.The ends are defined as the extreme limits of the parameter oriented from right(No pain) to the left (Worst pain).

Materials And Methods:

Totally 23 patients going for orthodontic treatment are enrolled into the study .Patients with fixed functional appliance ,removable appliances, or long term systemic medications as well as mentally handicapped patients are excluded from the study. All patients are given a leaflet with VAS for pain .The patients are requested to report the degree of pain they anticipated or experienced on the scale .A questionnaire was prepared and assessed among all 23 patients .
\end{abstract}

NAME :

AGE :

QUALIFICATION :

ANTICIPATED PAIN BY VAS :

EXPERIENCED PAIN BY VAS : NO PAIN

\section{WORST PAIN EVER}

NO PAIN WORST PAIN EVER

\section{Results}

The samples are collected from 23 patients from the age of 10 to 30.A 12 year old female anticipated a pain of 3.5 and experienced a pain of 8.4. A 13 year old male anticipated a pain of 7 and experienced 3.6 of pain.A 13year old male anticipated a pain of 6.8 and experienced a pain of 5. A 14 year old male anticipated a pain of 5.7 and experienced a pain of 7.8.A 14 year old male anticipated a pain of 5 and experienced a pain of 7.4.A 16 year old male anticipated a pain of 5.7 and experienced a pain of 5.3. Another 16 year old female anticipated a pain of 5.7 and experienced a pain of 6.7.Another 16 year old male anticipated a pain of 6.5 and experienced a pain of 4.8.An 18 year old female anticipated a pain of 7.5 and experienced a pain of 5.8.A 20 year old male anticipated a pain of 3.8 and experienced a pain of 4.8.Another 20 year old female anticipated a pain of 7.3 and experienced a pain of 3.6.Another 20 year old female anticipated a pain of 7.6 and experienced a pain of 6.4.A 21 year old female anticipated a pain of 2.7 and experienced a pain of 3.6. A 22 year old female anticipated a pain of 6 and experienced a pain of 4.4.Another 22 year old female anticipated a pain of 8.2 and experienced a pain of 6.1. Another 22 year old female anticipated a pain of 3.9 and experienced a pain of 8.2.A 23 year old male anticipated a pain of 5.5 and experienced a pain of 5.4.Another 23 year old male anticipated a pain of 4.9 and experienced a pain of 4.A 24 year old female anticipated a pain of5.3 and experienced a pain of 8.3.A 25 yearold female anticipated a pain of 6.6 and experienced a pain of 7.3.A 26 year old male anticipated a pain of 6.1 and experienced a pain of 6.7.A 27 year old female anticipated a pain of 4.7 and experienced a pain of 6.7.The mean of anticipated pain is 5.730 and standard deviation is 1.3887 amd the mean of anticipated pain is 5.787 and the standard deviation is 1.6391 which is shown in table 1 . The difference between anticipated and 
experienced pain mean is -0.0565 and the standard deviation is 2.0266 . The t value is -0.134 and $\mathrm{p}$ value is 0.895 which is shown in table 2 .

TABLE 1

Paired Samples Statistics

\begin{tabular}{|ll|r|r|r|r|}
\hline & Mean & $\mathrm{N}$ & Std. Dev iation & $\begin{array}{c}\text { Std. Error } \\
\text { Mean }\end{array}$ \\
\hline $\begin{array}{l}\text { Pair } \\
1\end{array}$ & $\begin{array}{l}\text { Anticipated Pain } \\
\text { Score by VAS } \\
\text { Experienced Pain } \\
\text { Score by VAS }\end{array}$ & 5.730 & 23 & 1.3887 & .2896 \\
\hline
\end{tabular}

TABLE 2

Paired Samples Test

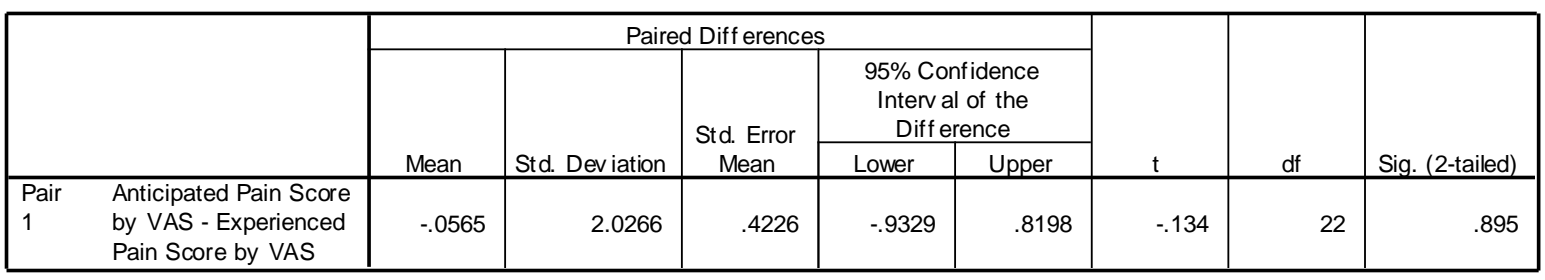

The results comparing the anticipated pain and the experienced pain following orthodontic treatment is shown. It is found that there is no significant difference between the anticipated pain and the real experienced pain

\section{Conclusion}

The anticipated pain and the experienced pain before and during orthodontic treatment can be same when a proper counselling and explanation of the procedure we are going to deliver is given.

\section{References}

[1] Krishnan V. Orthodontic pain: from causes to management--a review. Eur J Orthod. 2007 Apr;29(2):170-9.

[2] Kvam E, Bondevik O, Gjerdet NR. Traumatic ulcers and pain in adults during orthodontic treatment. Community Dent Oral Epidemiol. 1989 Jun;17(3):154-7.

[3] Huskisson EC.Measurement of pain .Lancet 1974;2:1127-31

[4] Miller MD,Ferris DG.Measurement of subjective phenomena in primary care research:the visual analogue scale.Fam Pract Res $\mathbf{J}$ $1993 ; 13: 15-24$

[5] Steiner DL ,Norman GR.Health measurement scales:a practical guide to the development and use.Newyork:Oxford university Press , 1989

[6] Scheurer PA, Firestone AR, Burgin WB. Perception of pain as a result of orthodontic treatment with fixed appliances. Eur J Orthod. 1996 Aug; 18(4):349-57.

[7] Furstman L, Bernick S. Clinical considerations of the periodontium. Am J Orthod. 1972 Feb;61(2):138-55

[8] Sergl HG, Klages U, Zentner A. Pain and discomfort during orthodontic treatment: causative factors and effects on compliance. Am J Orthod Dentofacial Orthop. 1998 Dec;114(6):684-91.

[9] Xiaoting L, Yin T, Yangxi C. Interventions for pain during fixed orthodontic appliance therapy. A systematic review. Angle Orthod. Sep;80(5):925-32. 